Session 1430

\title{
The Learning Environment and Faculty Development
}

\author{
Ardie D. Walser ${ }^{1}$, Barbara Bogue ${ }^{2}$, Janet A. Schmidt ${ }^{3}$ \\ ${ }^{1}$ City College and Graduate Center of CUNY $/{ }^{2}$ Penn State College of Engineering/ \\ ${ }^{3}$ Clark School of Engineering University of Maryland, College Park, Md.
}

\begin{abstract}
Since 1995 ECSEL an NSF sponsored coalition of schools (Howard University, MIT, Penn State, Morgan State, CCNY, University of Washington and the University of Maryland) has broaden its vision to include issues of student and faculty development, as well as, diversity. This coalition has produced a number of "best practices" and lessons learned from its major themes of Engineering Design, Student and Faculty Development and Diversity, Linkage to K-14, and Assessment/Evaluation. One such product produced by ECSEL is "In Their Own Words" (ITOW) a video and accompanying workshop (developed at Penn State) that addresses the "student experience" in the classroom and how to enhance the student learning environment. The video/workshop is aimed at a faculty audience with the aim to engender discussion about how students experience the learning environment and to raise faculty awareness of obstacles and universal student issues. Originally the video/workshop was design for Penn State, a large, predominately white institution. Recently, a second version of the video has been developed for export to campuses with a more diverse student population.

Using the promotion of the ITOW workshop as a model we will examine what one can do when trying to introduce a new idea (i.e. workshop, program, etc.) to an academic body such as an engineering faculty. In this paper we describe the process of implementation of ITOW by facilitators on three different college campuses, the impact on those campuses, and document implementation problems and solutions. Two of the campuses are majority institutions and the third is a minority institution. We will compare the experiences of each of the facilitators and discuss the problems each campus faced in running a workshop of this nature and how these issues were resolved. The initial response to a workshop of this nature, in some cases, can be unfavorable. The experience at the three institutions indicates that constant communication among the facilitators, faculty members, chairs and deans is a key to acceptance of a challenging workshop.
\end{abstract}

\section{Introduction}

The engineering schools of America are under great pressure to change engineering education in this country. Two major players in the push for this reform are ABET through its Engineering Criteria 2000 and NSF through its sponsorship of engineering education coalitions, such as ECSEL, FOUNDATION, SUCCEED and GATEWAY . The charge of each of these coalitions is to find ways to make change in the way engineering is taught. The traditional teaching method of chalk-and -talk is viewed as ineffective in equipping engineering graduates with the technical, communication and interpersonal skills needed by today's engineers. This necessitates creating faculty development programs that can challenge traditional practice and equip engineering instructors with the tools for a new way of teaching. While faculty development programs have not been prevalent in the engineering education culture, this is slowly changing ${ }^{1,2}$. A number of universities have implemented some form of faculty development program 
in their institution. Typically these schools are part of some form of coalition, many which are supported by NSF. Qualitative results from the dissemination of ITOW indicate that it is important that faculty, department chairs, deans and administrators play an integral role in its implementation.

\section{Background}

The Engineering Coalition of Schools for Excellence in Education and Leadership (ECSEL) consisting of, Howard University, Massachusetts Institute of Technology (MIT), Pennsylvania State University, University Park, Morgan State University, City College of New York, University of Washington and University of Maryland, College Park, was one of the first engineering education coalitions to be funded by the National Science Foundation (NSF). The ECSEL coalition's seven engineering schools are very different. Some schools are located in an urban setting while others are more rural, some are private while others are public, some have a majority student body while others student population are predominantly minority. Because of this diversity the coalition has been able to generate products that have been tested on a number of different type campuses, each with their own concerns and issues. Thus allowing feedback on these products from a wide variety of concerned faculty, students and administrators.

"In Their Own Words" (ITOW) is a video workshop that addresses the "student experience" in the classroom and the student learning environment. The video/workshop is aimed at a faculty audience and is used to engender discussion about how students experience the learning environment and raise faculty awareness of obstacles and universal student issues. The video/workshop was designed and implemented at Penn State and subsequently has been introduced to campuses throughout the country. The original video was designed for use at a large research institution. A second version of the video, developed at CCNY, has been made for export to campuses where professors are working with more diverse student populations, specifically where students are dealing with the same kinds of learning environment issues but not necessarily in a situation in which they are in the minority. Video II is also oriented toward smaller, and perhaps less research oriented institutions.

The video upon which the workshop is based reflects information gathered in interviews with twenty-four engineering students from the Penn State campus during the summer of 1996. The workshop development has been described in a previous publication $^{3}$ and assessment data for the workshops themselves will be presented in a separate publication. A full description of the project with copies of all tools will be available via a website (http://www.engr.psu.edu/itow) under development at Penn State (projected launch date, May 2001).

The workshop can be conducted in one hour with pauses after each of the three sections in the video for discussion. Guided facilitation of the discussion creates a highly interactive workshop where participants can raise questions and discuss issues that concern them. The third item is important: While workshop procedures are well documented the developers have designed the workshop to provide great latitude to any team that wishes to conduct this workshop on their campus.

\section{The Workshop on Three Campuses}

This portion of the paper documents the experiences of facilitator teams at three ECSEL institutions as they implemented ITOW-Penn State (PS), University of Maryland (UM), and City College of New York (CC). It describes the steps the teams took to introduce and gain broad acceptance for a workshop that, because it focuses on diversity and gender equity through the lens of learning enhancement, had the potential to be controversial. All three facilitation teams choose to focus presentations at the 
departmental level where there were meeting structures in place and where curriculum innovations were already underway or most feasible to initiate. At Penn State, approximately 200 faculty members in the Departments of Industrial and Manufacturing Engineering, Electrical Engineering, Architectural Engineering, Agricultural and Biological Engineering, Civil and Environmental Engineering and General Engineering. The Penn State team also facilitated ITOW for the College of Engineering Executive committee, for the annual, New Faculty Workshop, the instructional development class for Graduate Teaching Assistants and for the College of Education Climate Committee. At the University of Maryland, Mechanical, Aerospace, Biological Resources Engineering sponsored their own departmental sessions with about 10-12 people at each of these sessions. The facilitation team also did one general session with some faculty come from the other departments, but was not able to schedule individual meetings. The most resistant department was Electrical, who was not interested in any faculty training on any topic. UM reports that no administrators attended (except the chair and the two presenters) and women and minorities were likely to attend if they were in the department as this was often a topic of interest.

All workshops were presented to faculty groups by facilitators from within the Colleges or School of Engineering. At Penn State the team comprised Dr. Rose Marra, then Director of Instructional Services; Dr. Tom Litzinger, Director of the Leonhard Center for the Enhancement of Engineering Education and Barbara Bogue, Director of the Women in Engineering Program; At UM, Dr. Tom Regan (Associate Dean for Undergraduate Affairs, Professor, Chemical Engineering and Dr. Janet Schmidt (Director of Student Research, Psychologist); and at CC, Dr. Latif Jiji (Professor of Mechanical Engineering) and Dr. Ardie Walser (Associate Professor of Electrical Engineering). The fact that in all cases the facilitators were actively involved in collaborations with departments and individual faculty members increased their effectiveness as facilitators and of the workshop in general.

\section{How was the workshop introduced to your institution?}

(PS) We built a constituency from the ground up. In early development stages for the project, we met with the dean and then, at his suggestion, with faculty and department head focus groups to discuss the overall workshop objectives. We drew from the results to develop a workshop that met the project objectives at the same time it met identified needs of the faculty and department heads. We also decided that the workshop should be focused at the departmental level, rather than presented to generalized groups. We introduced the workshop at an Executive Committee meeting, comprising all deans and department heads in the College. After presenting the workshop, we handed out forms through which department heads could request a workshop; all but two requested workshops. We then coordinated the workshops through the departments, mainly in departmental retreats or faculty meetings. The dean was supportive from the beginning. We talked with him first and got advice on how to proceed to get optimum faculty involvement. He also collected the departmental requests for the workshop at the end of our initial presentation, which encouraged the high response rate.

(UM) We introduced the workshop via our chairs at an administrative Council meeting. Since we were approaching an ABET evaluation, we stressed the importance of faculty development and demonstrating to ABET that we were paying attention to undergraduate education. Given previous experiences with doing faculty development workshops in the College, we learned the best approach is to provide the workshops in EACH department (rather than general college offerings). Each chair was encouraged to support the workshop: to offer it during a faculty meeting 
time or during a lunch period (and provide a free lunch). The dean was generally supportive, but not directly involved.

(CC) We introduced the workshop by first presenting the video at the School of Engineering (SOE) advisory board annual meeting. The board consists of individuals from industry. Present at the meeting along with the board members were the Dean and Associate Dean of the SOE. The feedback we received was positive. With that response we proceeded to meet with the chairs of each department one at a time. We explained to them what we were trying to do and how we would like to do it and answered all of their questions about the workshop. We were able to take advantage of the experiences of both PSU and $U M$. We decided like UM and PSU that the best approach would be to conduct the workshop one department at a time. We also provided free lunch, but not in the SOE. Instead we held the workshop in a reserved dining room outside of the SOE. This was sanctioned by each of the chairs. We then went on an advertising campaign sending e-mail and flyers explaining to each faculty member who we are, who we are not and what we are trying to do. This was all done with a good dose of humor. The dean and chairs, once we made it clear we are not on a witchhunt, were very supportive. The chairs helped a great deal in making sure attendance was good.

\section{Did students play a role in the process and if so, what was their role?}

(PS) Student interviews provided the foundation for development of the workshop and the video as noted above. We also present ITOW regularly in our instructional development course for graduate students. The responses and interactions of graduate students have been very different from those of the faculty, often focusing on the issues from a student, rather than from the faculty point of view.

(UM) Students played a very effective role. A key step we did take was to review the video with our student council, composed of leaders from all of the various College of Engineering departments: we did this to try and head off the criticism that the PSU tape "is not like UMD"... the video was VERY well received by students who quickly endorsed $90 \%$ as being their classroom experiences. The $10 \%$ exception was the very low number of women faculty reported on the video (we have about 14 out of 190 faculty, apparently the number is worse at PSU AND the fact that we have a much more diverse student body than PSU). The students were so enamored with the exercise that several volunteered to attend the faculty training workshops with the facilitators (and we did take one senior Chemical Engineering major with us to two such sessions).

(CC) Yes students played a major role. Like the UM we were concerned about questions concerning the validity of comparing the issues of PS students as stated in the video to those of CCNY students. In order to deal with this concern we had a luncheon with 15 of our best students (GPA > 3.0), most who were SOE student organization leaders. These students filled out a four page survey with both multiple choice and essay type questions about the learning environment at CCNY. After the survey there was an hour long group discussion. From this we were able to determine that the PS students concerns are fairly universal.

\section{What was the faculty response before, during and after the workshop?}

(PS) We presented the workshop to over half of the College of Engineering departments with generally high attendance. The faculty response has been very 
positive. A sample of the overall responses from the departments at which ITOW was presented is:

Scale: $1=$ not effective, $5=$ very effective

Effectiveness of video - 3.54/5.00, departmental range: 3.14 to 4.11

Effectiveness of workshop - 3.69/5.00, departmental range: 3.27 to 4.32

The facilitation team also collated evaluation comments and suggestions for further action and presented this to each department head after the workshop along with a list of follow up workshops available.

(UM) Since attendance was voluntary and although the sessions scheduled during regular faculty meetings were "felt" to be more required, it was not too surprising that the turn out was not wonderful. And while all the chairs agreed to sponsor a session, we never were able to meet with all of the departments (we ran into the summer vacation before completing the cycle, then had our ABET visit in early fall, and never got back to all of the departments who had been missed). Faculty who did attend the workshops seemed to find the discussion and video tape interesting. As usual, they benefited from discussing these issues with their peers (as well as the facilitators). If they questioned the validity for our engineering school, we had our experience w/ engineering student leaders to refer to. After the workshops, we have done no systematic follow-up to assess the impact of the workshops, so we can't say for certain what faculty have done with the information in terms of application in the classroom.

(CC) We were able to conduct the workshop with every department in the SOE and attendance was very good. The faculty response was very positive. Here's a sample of the overall responses:

Scale: $1=$ not effective, $5=$ very effective

Relevance of Video to CCNY - 3.51/5.00, departmental range: 3.33 to 4.5

Effectiveness of workshop - 4.22/5.00, departmental range: 3.5 to 4.78

\section{What problems arose and how were they solved?}

(PS) Early on we facilitated a workshop that was successful, but fairly difficult. The department was a large one that had done a lot of work on developing hands on courses and had many members involved in revamping the curriculum. It became evident that they felt that we were telling them to do things that they had already done. This got in the way of the discussion of "Learning Environment" as opposed to "Learning Enhancement." We were able to correct mid-stream but learned from the experience to make sure that individual and group efforts to improve learning were recognized throughout the workshop and refocused the workshop up as a mutual exploration of how the learning environment can be improved for all students. This had the added benefit of developing the workshop as a continuous improvement process.

(UM) No big fights; some discussion on how to handle making students feel comfortable in the classroom.

(CC) We were able to foresee areas of potential major disagreement due to the PS and UM experiences and therefore were able to avoid them.

\section{What was the feedback from faculty, chairs and deans?}

(PS) Departmental follow up responses were varied and ranged from the development of a student/faculty code of responsibilities to team building and equity workshops 
to retreats focusing on education. The team also received individual feedback from participants via email and "hallway conversations." This kind of informal feedback indicated that the goal of the workshop to provide a catalyst for discussion about the learning environment, diversity and gender equity was being achieved.

(UM) We did get some suggestions for follow-up topics for future workshops...more on teaming (standard projects for teams, team dynamics); need for "solutions" to women and minorities in the classroom; the issue of how to balance research demands and teaching. A more distant type of "feedback"...as a result of doing these and a previous year's worth of ABET preparation faculty development workshops, the dean formed a "Faculty Affairs Committee" whose major focus is to organize faculty development activities to support me in my position as Director of Student Research. Our current topics are wider than teaching and include research opportunities, how to positively impact tenure decisions, etc.

(CC) We received numerous suggestions on other topics, as well as, tips on teaching. If anything the workshop was an opportunity for faculty to discuss the art and teaching and issue that concerned them and almost every department seem grateful or that opportunity. Presently a number of the departments are dealing with their ABET accreditation. However, ABET was not mentioned in any of the discussions.

\section{What are your recommendations for other institutions that are considering implementing ITOW or a similar workshop?}

(PS) Carefully develop support from the administrative power structure as well as ownership of the project among faculty. Early meetings, clearly stated objectives and setting clear expectations are all critical. In addition, early focus groups and our feedback to departments after each session brought faculty and department heads actively into the developmental process. ITOW is designed as a workshop that changes as it is delivered, drawing on the expertise and experiences of the participants as well as the research and literature on the learning environment and the experiences of women and men of color in engineering classrooms.

(UM) Go for 1.5 hours of time; try and hook the activity to a time when faculty are already available (e.g., faculty meetings); get more buy-in from the top; do more consistent follow-up; perhaps offer the workshop annually to new, incoming faculty who are more suggestible in the beginning (especially assistant professors); try and bring students if you can...they are the best sources of credibility!

(CC) Be up front and willing to explain what you are trying to do and keep to the point. The object is not to embarrass or reprimand but to inform and assist.

\section{How did the facilitators effect positive interaction among participants of the workshop?}

(PS) Using two or more facilitators is key. It provides backup for the lead facilitator who, in the effort to keep the workshop lively may miss good responses or lines of discussion. The second also becomes the primary note taker, making follow up sessions with the department heads more effective and providing changes for future workshops and workshop materials. The participants had lots of good 
individual suggestions and also enjoyed working on problems that came up such as how to get students to understand the breadth of a faculty member's responsibilities. All were added to the "Tip Sheet" which is handed out at the end of the workshop.

(UM) We had two facilitators (one male, one female) and we did a tag team, sharing the discussion and processing times. We shared answering questions, taking notes about the discussion, etc. One person was an Engineer, the other a group process expert, so the combination worked well...also, the participants themselves "processed" certain interactions, handled their colleagues when they made questionable comments. Very few difficult moments.

(CC) Very good. Like PS and UM we did a tag team, sharing the discussion and always directing the exchange back to the faculty. We tried hard to not take center stage. We took the position that we were not experts there to teach them how to do their job. Instead we were presenting an opportunity for each department to determine what issues were important and allowing them to solve those issues. When a difficult moment arose generally their colleagues would handle a wayward faculty member.

\section{Concluding Remarks}

The experiences of three institutions that introduced a potentially controversial workshop to large portions of its faculty demonstrate the strengths and pitfalls of various approaches. In each case the facilitators were sensitive to the position of the faculty making sure that they played a major role in determining the issues and finding ways to resolve them and were careful to communicate objectives and set expectations realistically. While this does not assure successful workshop facilitation, it does provide an environment conducive to success. The introduction of new ideas is often very difficult even if it the ideas are good ones. Changing traditional practices and the underlying a way of thinking are nearly impossible without acceptance at some level by faculty and administrators. Above we have given examples of three campuses that have introduced ideas that are often new and sometimes foreign to engineering instructors; the idea that the learning environment does matter and that equity and diversity issues are essential components of a good learning environment. Even though it has been documented through research that a student's environment has a major impact on how he/she learns, old habits (i.e. "chalk and talk") are hard to break. Too many educators in engineering continue to teach the way they were taught-it is what they know and it has apparently worked. However, the demands placed on today's graduating engineers are quite different, as is the make up of that graduating class-more is expected of both faculty and students. The question is how does one teach the teacher? Engineers by training and possibly by nature are problem solvers and have a need to know and understand. Make available information about teaching and learning, back it up with solid research and facts, reference their own problems in the classroom, help them to define the problem, and then work together to come up with solid solutions and practices.

\section{Bibiliography}

\footnotetext{
${ }^{1}$ R. Brent, R. Felder, T. Regan, A. Walser, C. Carlson-Dakes, D. Evans, C. Malave, K. Sanders, \& J. McGourty , "Engineering Faculty Development: A Multicoalition Perspective." 2000 Annual ASEE Conference Proceedings Session 2630, ASEE, June 2000
} 
${ }^{2}$ L. L. Bucciarelli, H. H. Einstein, P. T. Terenzini, A. D. Walser, ECSEL/MIT Engineering Education Workshop '99: A Report with Recommendations, Journal of Engineering Education, vol. , no. ,2000, pp.141- 149.

${ }^{3}$ Bogue B., R.M. Marra, T.L. Litzinger, and S. Johnson, "The Penn State ECSEL Learning Environment Workshop: A Progress Report." Creating a Global Engineering Community Through Partnerships, 1998 WEPAN National Conference, pp. 113-116.

\section{ARDIE D. WALSER}

Ardie D. Walser is an Associate Professor in the Electrical Engineering department of the City College and Graduate Center of the City University of New York. Dr. Walser is the Co-PI in charge of Student and Faculty Development for the NSF funded coalition ECSEL. He was the treasurer from 1996 to 1998 of the MIND division of ASEE and is presently the Awards Officer and Program Chair of that division. He has collaborated in the creation and direction of numerous faculty development workshops that have been held through out the country. He is the recipient of four different faculty awards including the faculty of the year award from the Eta Kappa Knu engineering honor society.

\section{BARBARA BOGUE}

Barbara Bogue is Director, Women in Engineering Program, Penn State College of Engineering, University Park, Pa. A recipient of the WEPAN WIEP award, she has coordinated two national conferences (topics: peace and the development of women engineers before and after graduation) produced a number of training and informational videos on engineering education and the learning environment, and is co-author of a workshop on the latter. Areas of research include programming for women in undergraduate engineering programs, women in media, and revolution. She is a member of the ASEE Women in Engineering Division and the Women in Engineering Programs and Advocates Network (WEPAN) Boards. She holds a B.A. from Nebraska Wesleyan University and an M.Sc. from the University of Southampton, U.K

JANET A. SCHMIDT

Director of Student Research, Engineering Administration, Clark School of Engineering, University of Maryland College Park, Md. 